\title{
The effect of the removal of the various accessory sex glands on the fertility of male rats
}

\author{
K. Queen, C. B. Dhabuwala* and C. G. Pierrepoint \\ Tenovus Institute for Cancer Research, Welsh National School of Medicine, Heath, \\ Cardiff CF4 $4 X X, U . K$.
}

\begin{abstract}
Summary. Accessory sex glands were removed from rats which were then allowed to mate with females.

Ablation of the ventral prostatic lobes appeared to have no affect on the animals' fertility whereas removal of the dorsolateral lobes or of the seminal vesicles induced complete infertility. Excision of the coagulating glands caused infertility in $12 / 16$ males.
\end{abstract}

\section{Introduction}

The accessory sex glands of the male are considered to provide a vehicle in which spermatozoa may be deposited in the female reproductive tract. Their individual contributions to the well-being of spermatozoa and to overall fertility are little understood. As Mann (1964) points out, the male accessory glands are set apart from other organs of the body by the highly specialized nature of their secretions as well as by their dose dependence for development and secretory activity on male hormone.

The motility of spermatozoa can be affected by the secretions of the accessory sex glands; Lindholmer (1974) converted the non-progressive flagellations of spermatozoa removed from the caput epididymidis into the motility pattern normally found in ejaculated spermatozoa after the addition of a small volume of seminal plasma. Morita \& Chang (1971) also showed that the secretions of the coagulating glands and those of the seminal vesicles acted beneficially together to maintain the motility of rat epididymal spermatozoa.

The necessity of the accessory sex glands for male fertility has previously been studied by ablation experiments but the results have been variable. This report considers the effect of the removal of the accessory sex glands of male rats on their subsequent fertility.

\section{Materials and Methods}

The animals used were 12-week-old Sprague-Dawley rats of proven fertility. They were bred in the animal house of the Institute and were of the Charles River strain. They were maintained with $12 \mathrm{~h}$ light (lights on at 07:00 h) $/ 24 \mathrm{~h}$ and food and water were always available. The animals were allocated to 8 groups.

In Group 1, the ventral lobes of the prostate were removed; in Group 2 the dorsolateral lobes of the prostate were removed; the seminal vesicles were excised from rats in Group 3 and the coagulating glands from those in Group 4. Equivalent sham operations were performed, with

* Present address: 342 Millington Boulevard, Bloomfield Hills, Michigan 48013, U.S.A. 
manipulation of the relevant organs, in rats of Groups 5, 6, 7 and 8 respectively. The animals were anaesthetized with ether and the ventral abdominal surface clipped and sterilized with chlorhexidine gluconate (Hibitane: I.C.I., Cheshire). A mid-line incision was used in each operation. For Group 1 rats, the ventral lobes of the prostate were exposed and dissected free of the peritoneum as far as the necks of the glands which were ligated with fine silk before removing the glands. Any bleeding was minimal and readily controlled by direct pressure.

The lateral lobes were excised from Group 2 rats in a similar manner. The dorsal lobes were exposed by delivering the seminal vesicles and the coagulating gland into the wound. The peritoneum over the dorsal lobes was divided transversely and the plane between the dorsal prostate and the rectum was developed by sharp dissection until the apices of the glands were revealed. The lobes were then removed piecemeal and bleeding controlled by direct pressure.

The seminal vesicles in Group 3 rats and the coagulating glands in Group 4 rats were excised by dividing the peritoneum midway between the apices and the necks of the conjoined structures and developing the plane between the two by sharp dissection downwards. Any small blood vessels were ligated with fine silk and once the glands were mobilized the necks were ligated with fine silk before excision.

The animals were allowed 1 week to recover from the operation. Then each male was caged with 2 females for 1 week. The males were killed by exsanguination by cardiac puncture under ether anaesthesia and the operation site examined. Patency of the vasa deferentia was assessed by the infusion of a solution of methylene blue into the lumina and confirmed in all cases by the appearance of the dye at the urethral meatus.

The females were caged separately following the mating period and when birth occurred the offspring were counted.

The operations and matings were repeated for Groups 1-3 and 5-7 and twice more for Groups 4 and 8.

\section{Results}

The results are shown in Table 1. Excision of the ventral lobes of the prostate (Group 1) had no effect on fertility (Table 1). Removal of the dorsolateral lobes of the prostate (Group 2) resulted in complete infertility in all animals. None of the experimental animals with excised seminal vesicles (Group 3) was fertile. Removal of the coagulating glands (Group 4) caused infertility in $12 / 16$ males compared with $3 / 17$ of the control animals.

Table 1. The effects of excision of accessory sex glands on fertility of male rats

\begin{tabular}{|c|c|c|c|c|c|}
\hline Group* & $\begin{array}{l}\text { No. of } \\
\text { males } \\
\text { tested }\end{array}$ & $\begin{array}{l}\text { No. of } \\
\text { females } \\
\text { tested }\end{array}$ & $\begin{array}{l}\text { No. of } \\
\text { females } \\
\text { littering }\end{array}$ & $\begin{array}{c}\text { Mean no. ( } \pm \text { s.e.m.) of offspring } \\
\text { per male }\end{array}$ & $\begin{array}{l}\text { Mean no. ( } \\
\text { per female }\end{array}$ \\
\hline 1 & 6,6 & 12,12 & 12,12 & $10 \cdot 7 \pm 1 \cdot 0,14 \cdot 3 \pm 1 \cdot 8$ & $5.33 \pm 0.36,7.42 \pm 1 \cdot 11$ \\
\hline 5 & 6,6 & 12,12 & 12,12 & $11 \cdot 0 \pm 1 \cdot 2,10 \cdot 7 \pm 2.5$ & $5.5 \pm 0.45,5.33 \pm 1.03$ \\
\hline 2 & 5,6 & 10,12 & 0,0 & 0,0 & 0,0 \\
\hline 6 & 5,6 & 10,12 & $6+.7$ & $6 \cdot 2 \pm 2 \cdot 8,11 \cdot 2 \pm 3 \cdot 8$ & $3 \cdot 1 \pm 0.91,6.09 \pm 1.46$ \\
\hline 3 & 6,6 & 12,12 & 0,0 & 0,0 & 0,0 \\
\hline 7 & 6,5 & 12,10 & $8,6+$ & $7 \cdot 8 \pm 2 \cdot 6,14 \cdot 8 \pm 5 \cdot 0$ & $7.38 \pm 1.81,5.90 \pm 1.87$ \\
\hline 4 & $6,4,6$ & $12,8,12$ & $6,0,1 \ddagger$ & $10 \cdot 3 \pm 4 \cdot 6,0,-\ddagger$ & $5 \cdot \overline{17} \pm 1 \cdot 59,0$, 二屯 \\
\hline 8 & $6,5,6$ & $12,10,12$ & $8,8+, 10 \S$ & $6 \cdot 0 \pm 2 \cdot 2,7 \cdot 0 \pm 1 \cdot 3,9 \cdot 3 \pm 2 \cdot 7$ & $3.0 \pm 0.77,3 \cdot 5 \pm 0.79,4.63 \pm 1 \cdot 10$ \\
\hline
\end{tabular}

* Group 1, ventral lobes of the prostate excised; 2 , dorsolateral lobes of the prostate excised; 3 , seminal vesicles excised; 4 , coagulating glands excised; 5-8 are the equivalent sham-operated groups respectively.

$\dagger$ One male died.

$\ddagger$ Litter cannibalized.

$\S$ One male died and 2 litters were cannibalized. 


\section{Discussion}

These results show that the ventral lobes of the prostate are not required for fertility in the rat but that the seminal vesicles and the dorsolateral lobes of the prostate are essential. Previous workers have not obtained such conclusive results. Walker (1911) induced infertility in $8 / 21$ rats by removing the ventral prostate and then subsequently produced the same effect in $4 / 5$ of the fertile animals by dorsolateral prostatectomy. Gunn \& Gould (1958) found that there was no effect on fertility or litter size following the removal of the dorsolateral lobes of the rat prostate and Pang, Chow \& Wong (1979) reported a reduced pregnancy rate in mice after removing the whole prostatic complex. However, Tisell \& Larsson (1979) showed that removal of the ventral and dorsolateral lobes of the prostate and of the seminal vesicles and coagulating gland has no effect on the quantitative and qualitative sexual performance of the animals.

The coagulating glands appeared to be necessary for fertility in most of the rats in Group 4. Engle (1926) reported only $40 \%$ fertile matings in the guinea-pig after removing the coagulating glands and Walker (1911) found approximately $60 \%$ of infertile rats after such surgery and the remainder produced only small litters. However, Lawson \& Sorensen (1964) and Pang et al. (1979) found no effect. Removal of the seminal vesicles severely reduced the pregnancy rate and litter size in mice (Pang et al., 1979) and complete infertility in guinea-pigs (Lawlah, 1930).

These differences cannot be explained at present. The operations could have different effects in different species as indicated by the cross-reactivity studies of Peitz, Foreman \& Schmitt (1979). The formation of the vaginal or copulation plug depends upon the secretions of the seminal vesicles and the coagulating glands (Gotterer, Ginsberg, Schulman, Banks \& Williams-Ashman, 1955) and Blandau (1945) has shown that spermatozoa cannot enter the uterus in the absence of the vaginal plug. However, spermatozoa removed from the cauda epididymidis of rats and injected directly in the uterine horns of oestrous females are capable of fertilization (Dyson \& Orgebin-Crist, 1973). These data and our own may mean that the function of the seminal vesicles and of the dorsolateral prostate is to provide a medium in which the spermatozoa are deposited in the female vagina and thence promote their progress through the cervix after which their secretions have no further purpose.

The authors are grateful to the Tenovus Institute, Cardiff for providing excellent operating and laboratory facilities.

\section{References}

Blandau, R.J. (1945) On the factors involved in sperm transport through the cervix uteri of the albino rat. Am. J. Anat. 77, 253-272.

Dyson, A.L.M.B. \& Orgebin-Crist, M.-C. (1973) Effect of hypophysectomy, castration and androgen replacement upon the fertilizing ability of rat epididymal spermatozoa. Endocrinology 93, 391402.

Engle, E.T. (1926) A morphological and experimental study of the proximal lobes of the prostate of the guinea pig, Cavia cobaya. Anat. Rec. 34, 75-90.

Gotterer, G., Ginsberg, D., Schulman, T., Banks, T. \& Williams-Ashman, H.G. (1955) Enzymatic coagulation of semen. Nature, Lond. 176, 1209-1211.

Gunn, S.A. \& Gould, T.C. (1958) Role of zinc in fertility and fecundity in the rat. Am. J. Physiol. 193, 505-508.
Lawlah, J.W. (1930) Study of the physiology of the accessory glands of reproduction of the male guinea pig. Anat. Rec. 45, 163-175.

Lawson, R.L. \& Sorensen, A.M., Jr (1964) Ablation of the coagulating gland and subsequent breeding in the albino rat. J. Reprod. Fert. 8, 415-417.

Lindholmer, Ch. (1974) The importance of seminal plasma for human sperm motility. Biol. Reprod. 10 , $533-542$.

Mann, T. (1964) The Biochemistry of Semen and of the Male Reproductive Tract. Methuen, London.

Morita, Z. \& Chang, M.C. (1971) Maintenance of the motility of rat epididymal spermatozoa in the presence of male accessory secretions. J. Reprod. Fert. 24, 247-254.

Pang, S.F., Chow, P.H. \& Wong, T.M. (1979) The role of the seminal vesicles, coagulating glands and 
prostate glands on the fertility and fecundity of mice. J. Reprod. Fert. 56, 129-132.

Peitz, B., Foreman, D. \& Schmitt, M. (1979) The reproductive tract of the male spiny mouse (Acomys cahirinus) and coagulation studies with other species. J. Reprod. Fert. 57, 183-188.

Tisell, L.-E. \& Larsson, K. (1979) Unimpaired sexual behavior of male rats after complete removal of the prostate and seminal vesicles. Invest. Urol. 16, 274-275.

Walker, G. (1911) The effect on breeding of the removal of the prostate gland or of the vesiculae seminales, or of both, together with observations on the condition of the testes after such operations on white rats. Johns Hopkins Hosp. Rep. 16, 223-253.

Received 4 September 1980 